\title{
Thinking Differently: A Visual Note Recording Strategy to Improve Learning
}

\author{
Dr.Alaa Zeyab \\ Assistant Professor at the College of Basic Education in Kuwait \\ Dr.Abdullah Almodaires \\ Associate Professor at the College of Basic Education in Kuwait \\ Dr.Faisal Almutairi \\ Assistant Professor at the College of Basic Education in Kuwait
}

\begin{abstract}
The use of visuals in the learning environment is increasing every day. The idea of connecting images with existing knowledge is one way to effectively learn and remember. Since visual literacy has become one of the most important concepts in education today, finding a new way to present and understand information about the concept is an essential part of the learning process. The purpose of this study is to explore the importance of using visual note recording (VNR) in the learning process, and how the participant perceives visual note recording as an aid to thinking and recalling information. A qualitative methodology was used to gain in-depth understanding of visual note recording (VNR) in the learning process. Interviews were used to collect information from five participants representing different nations. Participants were asked questions designed to explore their experiences in using VNR as an aid to enhanced thinking, and to determine how they define the activity of visual note recording.

Findings from this study show that VNR can have a great impact on students' learning ability. The study demonstrates that the use of VNR leads to recalling information more easily, simplifying complex ideas, and enhancing critical and visual thinking skills. This study also points out that VNR is constructive and supports authentic student learning opportunities.Originality: Since there is a paucity of research on VNR and its use in the learning process, either in educational institutions or business organizations, this paper adds value to educators, practitioners and policy-makers.
\end{abstract}

Keywords: visual note recording (VNR), sketchnoting, learning process, cognition, memory recall, visual literacy, visual thinking, critical thinking.

DOI: $10.7176 / \mathrm{JEP} / 11-2-02$

Publication date: January $31^{\text {st }} 2020$

\section{Introduction}

Visual notes are sketches that involves a thoughtful amalgam of text and imagery to convey basic ideas from teachers' lectures and student-peer discussions (Childers et al., 2013). Visual Note-Recording (VNR) which is synonymous with visual note-taking or sketch-noting is the process of graphically recording or representing information non-linguistically (Pillars, 2016). It is the process of communicating or presenting ideas without using large amounts of written language (Childers et al., 2013). In other words, a note taker uses phrases, words and symbols to present a whole concept. These notes are created in real-time while actively listening to lectures and discussions (Paepcke-Hjeltness \& Cyamani, 2017). Students not only use traditional writing tools (pen, pencil and paper) but also mobile digital technology (iPad, Android devices) and digital tools such as word processing software and apps (Stacy \& Cain, 2015).

Educators are beginning to realize that this visual note recording can be initiated as a learning strategy that not only help students learn, but also creates a fun motivator for encouraging students to learn and for releasing stress (McGregor, 2018; Wammes, Meade, \& Fernandes, 2016). The research is driven by the supposition that VNR can be a motivational tool to develop creativity and synthesize information visually. However, there is a lack of research emphasizing how and where to use this activity in order to get the optimal benefit from this strategy. Therefore, an investigation of VNR, its significance in the learning process, and how to effectively integrate the strategy into classrooms would provide significant depth to the current field. It is also important to define visual note recording as it relates to the experience of the individuals using this method in the learning process. To do that, there is the need to explore the connection between visual note-recording and learning, and explore how students and educators can benefit from applying this spontaneous habit into an existing meaningful strategy that has impact on student learning.

In this study the researchers investigated if VNR as a visual thinking strategy can enhance critical thinking skills, increases memory and facilitate understanding of complex topics based on the perspectives of visual note recorders and journalists who are involved in freelance sketchnoting gigs. Therefore, this research shares insights from interviews with visual practitioners regarding the importance of visual note taking or recording. It builds on 
many previous studies concerning how using images or visuals in general can enhance learning. To fulfill this purpose, four research questions were formulated as a foundation for this investigation:

RQ1: For what purpose were the practitioners using VNR?

RQ2: What are the benefits and limitations of applying visual note recording for learning as perceived by the visual practitioners?

RQ3: How do the visual practitioners report their perception of critical thinking skill building as facilitated by VNR?

RQ4: How do the visual practitioners define visual note recording?

\section{Literature Review}

\subsection{Visual Note-Recording and its Significance}

Visual note recording is the same general concept as sketching, but it is more than just doodling or scribbling (Mills, 2019). The difference is that VNR focuses on simple drawings and typography and is used to largely process lectures. It is also a perfect skill for keeping a diary or journal that explores thoughts and feelings, for documenting processes in a business project, and in any field or situation where retaining information is key (Mills, 2019). It is a process of representing ideas non-linguistically (McGregor, 2018). However, there are claims that visual note taking practice does not involve thinking, and is often associated with doodling or making spirals or squiggly patterns while talking on the phone (Brown, 2014; Schott, 2011). It is often misunderstood to as an aimless and wasteful scribble or an activity that does not require much thought (Mills, 2019; Schott, 2011). On the contrary, visual notes are anything but absentminded (Mills, 2019). Studies have also shown that making spontaneous drawings in general helps provides stress relief which has a positive effect on improving focus (McGregor, 2018; Wammes et al. 2016). Therefore, we can accentuate that relaxation helps with retention of information, and both of these benefits can be linked with visual note recording.

According to Brown (2014), there are visual learners, auditory learners, and kinesthetic learners, although these three learning types are not isolated. Effective instruction techniques include a variety of methods to fit the needs of all learners, and teaching using multiple models of information delivery enhances student learning performance (Wilson, 2011). Visual note recording can be incorporated into instruction as it balances visual, kinesthetic, and auditory learning (Udomon et al. 2013). The learner who sketches and using text simultaneously is creating a visual note while listening. Combining these three learning methods into one technique creates an ability for deeper understanding of the concepts being presented (Brown, 2014).

Kinesthetically, the action of creating visuals helps students incorporate new knowledge and improves recall, whether students are listening to lectures or reading lessons (Udomon, et al., 2013; Ainsworth et al., 2011). Drawing and idea-sketching are viewed as an important aspect of open discussion and communication techniques (Pfister and Eppler, 2011). Students listening to tape recorded lessons were found to recall the information better when they visually recorded their notes while listening (Andrade, 2010). Brown (2014) had demonstrated improved cognition in students who doodle. In the study by Ainsworth et al. (2011), students became more engaged in science lessons by incorporating visual note recording, and drawing what they were learning.

There have been several studies exploring how the visual note recording technique affects recall ability (Pillars, 2016; Ainsworth, Prain, \& Tytler, 2011; Andrade, 2010). When people use purposeful visual note recording, they make visualization a core part of the learning process. VNR then becomes another strategy to help us think, comprehend, and recall information (Beatty, 2013; Brown, 2014; Mead 2019). In addition, some research adds that visual note recording during a learning setting, if used purposefully, would stop the person from day dreaming (Andrade, 2010; Fernández-Fontecha et al., 2016). On the other hand, Chan (2012) shows no significant effect on his learner regarding using VNR spontaneous drawing and the subsequent recall of information. However, there are other studies that confirm the importance of effectively using visuals in the learning process (Wammes et al. 2016; Udomon, et al., 2013; Mayer, 2009), including evidence of how combining words and images facilitates faster memorization (Paepcke-Hjeltness, Mina \& Cyamani, 2017). These studies suggest that students who can move information more quickly into long-term memory do not experience as much cognitive overload when faced with new knowledge. With this in mind, it makes sense to integrate visual note recording into the learning process to increase students' learning and memory retention (Wammes et al. 2016; Udomon, et al., 2013; Semetko \& Scammell, 2012). It is claimed that the brain processes images 60,000 times faster than text and visuals are often easier to understand ad remember than text (Trafton, 2014; Semetko \& Scammell, 2012).

Based on the above discussion, a working definition of VNR had to be developed. Although Brown (2014) states that sketchnotes or doodles are spontaneous that help one think, such simplistic definitions are inadequate. There is the need to redefine the concept as a purposeful activity that can improve the learning process. It is also important to consider VNR as a communication learning tool, and a multimodal approach to visual thinking that can help prompt memory and develop a higher level of understanding (Zucker, 2019; Fernández-Fontecha, O'Halloran, Tan \& Wignell, 2016). Moreover, VNR involves visual listening and visual idea generation (PaepckeHjeltness et al. 2017). This indicates that effective VNR requires students to listen, analyze content, write, and 
doodle. Therefore, for the purpose of this study VNR is defined as a mix of rich visual notes and visual elements namely sketches, doodles and shortened words (Rohde, 2013) that can help create an external memory whose only importance would be its later use, for example to clarify, and organize information. In other words, it is a visual representation of imparted information or an experience (Mills, 2019). This multifaceted definition was used in the current study to guide research design and to investigate participants' perceptions of visual note recording.

\subsection{The Link Between Visual Note Recording and Visual Literacy}

Visual literacy extends beyond the traditional concepts of reading and writing, and includes visuals (Tillmann, 2012). There are many definitions of visual literacy and many authors and scholars have defined this concept to meet the needs of individual studies. Visual literacy can be achieved through graphics as well as text (Elkins, 2008). It is defined as the ability to interpret and use images in communication for visual thinking, creativity, and design, all leading to improved comprehension and understanding (Matusiak, Heinbach, Harper \& Bovee, 2019; Beatty, 2013; Felton, 2008). It is important component of today's educational environment because of the tremendous expansion in the use of smart technologies that employ the Internet, smart phones, and computers (Tillmann, 2012; Matusiak, Heinbach, Harper \& Bovee, 2019). Visual note recording helps improve visual literacy skills as well as visual thinking (Walker, 2012; Tillmann, 2012; Fernández-Fontecha et al. 2016). The ability to analyze and interpret visuals alone "is not by itself sufficient for full visual literacy; it must be accompanied by some ability to create visual material"(Brumberger, 2011, p. 21). Being visually literate and taking part in creating visuals, such as in purposeful visual note recording or idea-sketching, relieves cognitive overload and improves recall of important information (Lohr, 2008).

\subsection{Visual Note Recording as a Visual Thinking Strategy}

Visual thinking is a combination of creative and critical thinking. is a way of thinking in pictures (Moeller, Cutler, Fielder \& Weier, 2013). Visual/spatial thinking involves purposeful use of an individual's eye to develop mental images or mental representations that are crucial for learning (Mccormack, 2017). In other words, it is a way of processing information in pictures, even seeing letters and words as pictures (Walker, 2012).

VNR is a purposeful and multimodal approach to visual thinking (Fernández-Fontecha et al., 2016). Studies discussing the strengths of using visual thinking as a learning strategy mostly agree that visual thinking strategies foster the development of creative and critical thinking skills and that it is important to overall learning (Mccormack, 2017; Fernández-Fontecha, et al., 2016; Moorman, 2013; Moeller et al., 2013; Walker 2012; Goldschmidt, 2001). Visual thinking strategies not only helps improve comprehension of complex information but can also facilitates remembering (Moeller et al., 2013). Comprehension helps move information to long term memory, making recall easier. However, research suggests that teachers looking for strategies to help students with memorization, creativity, critical thinking skills, and comprehension need to make sure that both words and pictures are used in balance because both visualization and language are essential for improved cognition (Fernández-Fontecha et al. 2018; Paepcke-Hjeltness et al. 2017; Mccormack, 2017). The iterative process of visual and critical thinking, reflecting and doing or visual sense-making is at the core of visual note taking process (Paepcke-Hjeltness \& Lu, 2018).

In reviewing the limited current literature available on visual note recording, there is a clear picture of how visualization is connected to how people create meaning, especially in the learning process.

\section{Theoretical Framework}

The theories underpinning this research are dual coding theory proposed by Paivio (1990) and constructivist learning theory. The dual coding theory pertains to visual note taking or recording as well as sketchnoting and doodling. At its core, VNR applies dual coding theory by combining both text and images (Paivio, 1990). The theory posits that individuals can perceive and recall information better if it is presented visually along with verbal recordings and expressions. In other words, an individual's brain is engaged in two ways and consequently in a better position to retain information. Overall, the theory advances the notion that the use of images and words would increase engagement, understanding, and retention in the classroom. Dual coding theory is not only a cognitive theory but also a constructivist theory of literacy (Sadoski \& Paivio, 2012).

The way visual note taking works to enhance learning is explained using the theoretical perspective of constructivism (Ertmer \& Newby, 2013; Vygotsky, 1978). VNR is a tool of presenting knowledge components and their interrelations and assists learners to effectively absorb, understand, and apply concepts. Students or individuals construct knowledge by taking in new information, comparing it to what is already known and creating new knowledge (Pritchard, 2009). In this way, students or other individuals are able to construct meaning and interpret reality through interaction with others and with new knowledge (Mills, 2019; Pritchard \& Woollard, 2010; Vygotsky, 1978). Visual note recording can be related perfectly to constructivism because it involves external thought and creative insight, learning through self-reflection and linking this with existing information and personal experiences (Pritchard, 2009). This helps in memory recall, brainstorming, and simplifying concepts. 
Like any other skill, it takes time to learn how to record visual notes and improvement requires practice. By incorporating Vygotsky's (1978) zone of proximal development, instructors can interact and explicitly teach learners how to construct visual notes and model VNR themselves. This would involve building scaffolds into instruction to ensure that students take better notes, for example using guided notes, lecture handouts or outline of the material to be covered. This strategy, also known as scaffolding, can provide learners with enough support in the initial stages of learning of a new topic, reflect, think critically, develop abstract concepts and construct knowledge (Mills, 2019; Haydon, Mancil, Kroeger, McLeskey, \& Lin, 2011).

The diagram below (Figure 1) depicts a unified theory for VNR which includes dual coding and constructivist learning theories. The primary implication of dual coding theory is that the external knowledge presented in both the textual and visual form can certainly be encoded meaningfully. This is also the key implication of constructivist theory of learning which proposes that learners can construct knowledge from examples or through scaffolds.

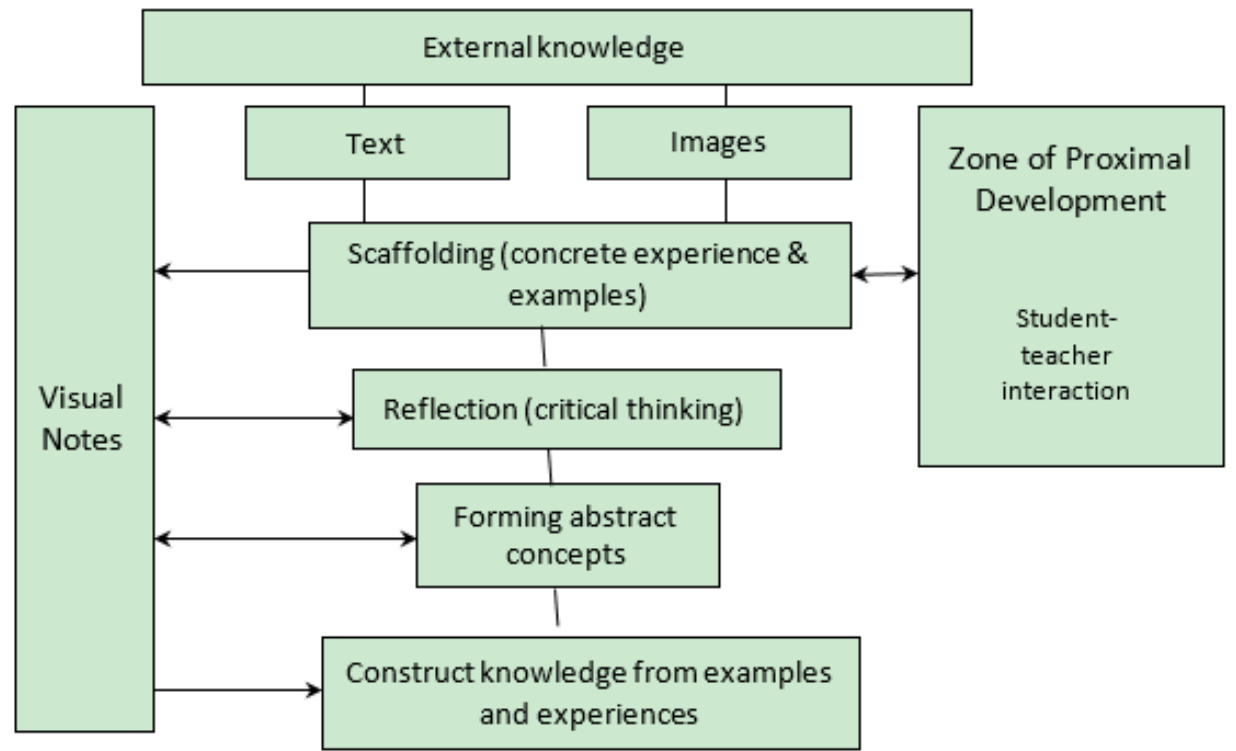

Figure 1: A theoretical framework for visual note recording

\section{Methodology}

Within an exploratory qualitative framework and an interpretivist stance, an inductive approach was adopted in this research to derive themes (Thomas, 2006). The researchers posit that there are multiple realities, and therefore VNR, a real-world phenomenon, is best understood by studying it in detail within the context in which it occurs (Creswell, 2012).

\subsection{Participants \& Setting}

Non-probability sampling, which is considered the most appropriate sampling strategy for a qualitative study (Merriam, 2009) was used to select a limited number of people from the education and business sectors who use visual note recording as part of their professional lives. Visual practitioners from different countries around the world were identified as the target population for this study. The rationale for such a selection process was that visuals transcend culture and spoken language (Mills, 2019). Moreover, they were involved in visual note recording for different settings, for instance business meetings, workshops, and university lectures.

The sampling approach was purposeful and the participants represented a range of demographics in keeping with the demographics of the site institution, including region of origin and gender. The qualitative sample, which consisted of five visual practitioners, was selected based on the knowledge that the participants were using visual note recording as a visual learning/thinking strategy in their teaching. Over 30 potential participants were contacted and only five agreed to take part.

The sample size was considered appropriate because Creswell (2014) argues that the sample size depends on the approach adopted by the researchers. Creswell (2014) recommends 4-5 cases as sufficient for a case study, 12 cases for narrative inquiry, and 3-10 participants for qualitative phenomenological research. These recommended sample sizes provided valuable direction for the current study and resulted in the selection of five participants. Prior to data collection, the participants signed consent forms that their participation was voluntary and they could choose to end the interview at any time.

\subsection{Data Collection Procedures}

In qualitative research, it is important to look deeply into only a few specific cases in order to get an in-depth 
understanding of the subject being studied (Creswell, 2012). Therefore, in-depth interviews were used for this research to allow the researchers to investigate the phenomenon of visual note recording in a more meaningful way.

The semi-structured interview guide (See Appendix B) developed for this study allowed the researchers to ask questions in a casual and conversational manner. It consisted of open-ended questions, but follow-up questions (why or how) were used to probe and motivate the participants to elaborate further about their perceptions of using VNR. Typically, these interviews were conducted face-to-face, either in person or using Skype technology. A face-to-face request included asking people if they were willing to participate. Once the sample was chosen, participants were asked questions designed to measure their experience in using visual note recording to advance visual thinking and foster critical thinking. The interviews were audio-recorded, and a copy of the participant's visual note recording was also collected during the interviews (See Appendix C, D \& E). Each interview took approximately 20-30 minutes. Notes were also made during the interviews.

\subsection{Data Analysis Procedures}

Data analysis followed immediately after the interviews. The data was organised prior to transcription by reading and reviewing the interview transcripts until themes or patterns emerged. This involved creating codes, sorting the information into categories, separating the data based on themes, and organising themes according to research questions. In other words, Braun and Clarke's (2012) thematic analysis procedure was used. This procedure allowed reducing the interview data and in developing four relevant themes that helped describe the central phenomenon. When the analysis was complete, a statement of the findings was made.

\subsection{Ethical Considerations}

To protect anonymity and ensure confidentiality, information (e.g., participants' names) that would link to subjects' responses was not collected. However, details of location, gender and profession were collected. Pseudonyms were used to identify the participants responses, for example "Ariel" or "Elsa."

On completion of data analysis, all recordings and notes were kept in locked files. Handwritten notes were destroyed as soon as they were scanned into a personal computer. The documents, audio recordings and consent forms were stored in a personal computer and a password was used to protect the file. All the collected data will be destroyed three years following the completion of the study.

\subsection{Trustworthiness}

Trustworthiness of the findings was established by meeting the criteria for quality in qualitative research, namely credibility, transferability, confirmability, and dependability as advocated by Lincoln and Guba (Korstjens \& Moser, 2018). Credibility was ensured through persistent engagement with participants and member checking. The researcher used member check to verify each statement by sending the findings to the participants via email to determine the accuracy of the interpretation of their responses. Based on their responses, minor changes were made.

Although the results cannot be fully generalized, the results can be transferred to other contexts or settings with other participants. Transferability was facilitated by the researchers by using thick description of the participants' experiences in different settings. Data saturation was also reached when the researchers found that there was enough information to repeat the study and when further coding was no longer possible (Fusch \& Ness, 2015). Another strategy used for establishing the trustworthiness of the study was the development of a research audit trail (Carcary, 2009). In other words, dependability and confirmability was established by recounting the steps taken by the researchers from the start to the development and reporting of the findings (Korstjens \& Moser, 2018). In this study, the audit trail shows that the researchers were transparent in the key decisions taken throughout the research process. Using the audit trail and notes made, other researchers can see how these results were obtained.

Reflexivity, which is essential for ensuring the transparency and quality of qualitative research was ensured by describing the contextual interconnecting interactions between the participants and researchers (Dodgson, 2019). In order to demonstrate reflexivity, the researchers in this study maintained a reflexive journal to make regular entries during the research process, and fostered a reflexive dialogue to reach consensus and foster reliability (Lincoln \& Guba, 1985). The researchers realized that the primary questioner would have a bias towards visual note recording. To balance that bias, negative case analysis was used by asking respondents to explain how and when visual note recording might not be beneficial in order to obtain an alternative explanation (Brodsky, 2008).

\section{Findings}

In this section, the researchers analyze and interpret the collected qualitative data by coding the data and categorizing the text into segments. Data coding continued until no new codes occurred in the data (Saunders et 
al., 2018). Since all the respondents used many of the same terms repeatedly there were increasing instances of the same codes, but no new ones. Saturation was reached at the point at which the data did not yield any new emergent themes (Saunders et al., 2018). On completion of the thematic analysis, four broad themes were identified: (i) VNR enables visualizing and simplifying complex concepts; (ii) affordances and constraints of VNR; (iii) VNR enables visual recall and memory; and (iv) lack of unanimous definition of VNR. The participants' responses within each theme are explained here.

\subsection{Visualizing and Simplifying Complexity}

Reading through the interviews, the researchers found that the participants had used visual note recording since childhood, particularly in school. "I have always used sketchnotes and doodles, ever since I was a kid. Even in school" stated Elsa. Most of the participants (4 out of 5) responded that they had used it as a tool for processing meetings, lectures, and ideas, because they were sometimes bored in class. However, they related the visual note recording with specific concepts especially when they thought they needed more explanation to understand or clarify the concept for themselves. Ariel explained, "I think it is really useful for getting a deeper level of understanding for me." When they were younger, they did not have that deep awareness of the importance of visual note recording or how it can reflect positively on learning and understanding. They only used it because they had the feeling it was a like doodling which helped them achieve better understanding. Ariel further noted that "I am trying to use visuals to explain things or make something clearer." As adults, each of the participants had applied VNR in their job. Some of them have academic positions while others have their own businesses. Elsa spoke of learning the importance of visual note recording this way: "I did not consciously use it as a learning tool, although later I realized it was a learning tool."

Visual note recording was not just being used for personal purposes. The participants had redefined the concept and were using it as a means of communication and showing it to teachers and colleagues as another way of seeing information. Belle explained how she uses VNR for visualization as part of her business. When clients asked for more clarification, she said, "they asked me if I would start drawing [the visuals] large enough for all of their participants to see." Ariel described a brainstorming session that required sketch noting: "People were throwing out ideas in a brainstorming session and I was able to visually capture all those ideas by visual note recording." Whether the participant used visual representations for business or education, all the participants referred to visual note recording as a tool for making complex concepts easier to understand. "Yes, it helps to simplify so that people can actually make decisions," Ariel said.

The following three comments illustrate how visualizing through visual note recording works: "[I use] visual learning to reinforce strategic planning, creative problem solving, and brainstorming" stated Belle. According to Ariel "if we capture a meeting visually, it is so much more memorable." Mulan was of the opinion that "visual thinking allows me to effectively communicate something that is complex.". All the participants seemed to have extensive experience in using visual note recording in their professional lives. They had also used VNR in their personal lives; whether in school or at home, by drawing or doodling in classrooms, or simply while listening on the phone. Overall, visual note recording is one way of visualizing context and simplifying meaning. In other words, it is a means of simplifying seemingly complex concepts or problems and it visually explains those ideas or complexities in plain language.

\subsection{Affordances and constraints}

This theme refers to participants' beliefs about the real and possible uses or limitations of VNR as a tool for learning, especially for processing meetings, lectures, and ideas. For the purpose of this study, affordances refer to the support that VNR offers participants. It includes all actions that are physically possible when using VNR as a creative literacy tool. On the other hand, constraints refer to restrictions or limitations.

All participants were asked if they thought there were any instances when visual note recording is not beneficial. Only two of the five participants could think of an example of when this was true. Both these participants agreed that VNR is not beneficial if it distracts the listener from the lecture or the material they are supposed to be focusing on. Elsa said, "I think it can be not beneficial when it can be a source of distraction." Jasmin explained, "I hate to sound too negative. Although it can be a distraction from the learning focus it helps day dreaming." Three participants agreed that any form of visual note recording while learning is important. By suggesting that the experience was 'appealing' and 'remarkable', the participants claimed that the affordances of VNR can alter the nature of learning, for example enhance visual literacy and visual thinking. Belle explained it this way: "It gives me the opportunity to concentrate or focus on a topic and reduces stress" and added that "just as a computer and a laptop are tools video notes are similar but more powerful." These responses suggest that the advantages outweigh the constraints. The difficulty, however, is in defining what visual note recording is exactly.

\subsection{Visual memory or recall}

Although the interviewees were not questioned specifically if visual note recording was helpful for recall, three of 
the five participants answered affirmatively that this approach aided visual memory. The responses suggest that VNR is an important tool that can be used for remembering and recalling information. Belle discussed the benefits for students who use VNR while listening to lectures or while studying: "When students are administered tests, they can remember, 'What was I drawing? What was I doing? What was I thinking?" Elsa explained a similar scenario this way: "I remember what I had sketched, or doodled. I remember the motions that my hand made, and that brings me back to the moment where I was listening and learning."

The respondents also maintained that VNR allowed them to "memorize almost anything as video notes helped create associations and visual mental images" (Ariel). According to Jasmin "when I visualize something it is not very vague or ill-defined. It is vivid, detailed and realistic." Recalling information was a constant and recurring theme. The use of visual note recording helped visualize lectures and remember concepts.

\subsection{Lack of Unanimous Definition}

The final interview question asked the participants for their definition of visual note recording. Each participant had some difficulty defining the phenomenon. Their responses were different but they seemed to imply that VNR was a visual representation of what was taught to them or what they learnt from previous experiences. Each definition is included here for comparison. Mulan stated, "I think that it is a way to connect visuals and verbal explanation. So, visual note recording is a visual representation of complex ideas or concepts." Belle asserts, "I believe that visual note recording occurs any time you put pen to paper." Ariel elaborated, "I have always thought that visual note recording involves drawing and making notes, and although you are not thinking about what you are drawing, it is yet a calming, meditative activity." Elsa said, "It's a learning tool that involves a visual component, that is words, pictures and images." Finally, Jasmin stated, "It is like brief expressions of visual ideas that grab your attention. They are like a momentary activity that requires focused visual attention." The responses demonstrate how difficult it is to put into words a concept that is about visualization.

\section{Discussion}

The findings provided a theoretical understanding of the importance of use of visual note recording. Here, we would like to interpret the findings and address the research questions.

Research question one asked for what purpose were the practitioners using VNR. The themes 'visualizing and simplifying complex concepts' and 'affordances and constraints' provided answers to this research question. Responses suggest that some of the participants have employed VNR, or what they sometimes call sketchnoting, for as long as 20 years to better understand concepts or problems. Other participants, who did not have many years of experience using VNR, still had the same common impression about it. There were many words and phrases, for example 'clarify concepts' or 'explain complex concepts' that showed up in the participants' responses that shared the same meaning. Overall, the responses provided justification why one should use visual note recording. Simplifying complex ideas, remembering, and creativity were all common expressions found in the interviews. These results aligns with previous studies (for example Matusiak et al., 2019; Fernández-Fontecha et al. 2018; Paepcke-Hjeltness et al. 2017; Rohde, 2013; Ainsworth et al., 2011; Pfister \& Eppler, 2011; Andrade, 2010) that have claimed that visual note recording allows individuals to brainstorm ideas, improve memorization or recall ability, and enable the visualization of learning,

Research question two sought to uncover the benefits and limitations of applying visual note record for learning as perceived by the visual practitioners. The themes 'affordances and constraints' and 'visual memory or recall' provided answers to this research question. All the participants agreed that visual note recording is a tool that can be used in any learning process, both in business organizations or educational institutions. The participants used VNR in their lectures or meetings not because they were bored, but because it was 'appealing' and 'remarkable'. Findings suggest that VNR is a powerful tool that enhanced visual literacy and provided the opportunity to focus on what the participants were doing and in alleviating pressure. These results are corroborated by a wide body of existing literature, for example Mccormack (2017) and Goldschmidt (2001) who claimed that taking visual notes while listening to a lecture could engage students and help them to focus. Moreover, some researchers mentioned that writing by hand while listening to the subject reflects on cognitive skills and remembering the information for a longer time. (Mills, 2019; Moorman, 2013; Walker 2012). However, two of the five participants stated minor reasons for when, why, and how visual note recording can be considered as not beneficial. It is evident from the findings that video notetaking can be source of distraction. This finding contradicts literature which shows that visual note taking, when used purposefully, can be beneficial as it can provide multimodal affordances such as interactivity and creativity (Mills, 2019; Matusiak et al., 2019; FernándezFontecha et al. 2018).

In research question three, we sought to determine if visual note recording, a visual thinking strategy, can facilitate critical thinking. The theme 'visual memory or recall' provided answers to this research question. The visual practitioners considered VNR to be very important for harnessing their thoughts in a creative manner. By claiming that they were able to "perceive more things in their sketches" and communicate further meaning, the 
participants were suggesting that they were able to create associations with past experiences through visual mental images. They also seemed to incorporate the additional step of self-reflection as well as interactions. Research has consistently shown that individuals with visual literacy skills have the ability to engage with visuals at a deeper level and the skills to critically evaluate the images (Paepcke-Hjeltness \& Cyamani, 2017; Paepcke-Hjeltness et al., 2017). Overall, the results show that mastering memory techniques allowed the visual practitioners to take control of their own learning, to overcome challenges and to develop the skills of critical thinking, all while having fun.

Finally, research question four sought to determine the meaning of visual note recording from the viewpoint of the participants. The theme 'lack of unanimous definition' provided answers to this research question. Previously, the definitions of visual note taking/recording or sketchnoting were not comprehensive. Most people related visual note taking to visually recording ideas absent mindedly (Miles, 2019). The other definition is purposeful visual note recording, which is used or practiced by individuals who use it as a tool (FernándezFontecha et al., 2016). Throughout the interviews, participants were unable to come up with a broad definition of visual note recording. However, they agreed that VNR is a strategy to remember, visualize and activate prior knowledge in order to reach a better understanding of a concept. Results show that the participants responses appeared to be in line with the definitions of Mills (2019), Paepcke-Hjeltness et al. (2017) and McGregor's (2018) that visual note taking, line sketchnoting, or doodling, is spontaneous, creative, motivating and involves a combination of linguistic (words) and nonlinguistic representation (images).

\section{Conclusion}

This study reported the findings of a qualitative study that investigated visual practitioners perceptions of VNR for learning in the context of use. The results of this study indicate that basic visual literacy skills, visual thinking and critical thinking are required in creating video notes. The study concludes that visual note recording is the visualization of complex ideas in a simple, understandable format. Some of the key findings suggest that using VNR can support problem solving, aid the learner brainstorm and sort through intricate details, improve information recall and help learners develop a deeper understanding of new information.

This research contributes to qualitative research, to the discourse on visual literacy and visual thinking, and to inform instruction in education. It makes a unique contribution to the field, in that few studies have investigated the theories driving visual literacy. Since the findings suggest that the use of video notes can develop the ability to create images, its implementation in classrooms would help students learn to decipher, understand and communicate with images in a better manner. Practices guided by constructivist and dual coding theories could assist in giving specific or definite form to abstract ideas and allow students to connect verbal representations to context-appropriate visuals. Therefore, this study can help teachers and practitioners to see the relevance of these two theories to their classrooms.

The findings can be used by educators as a guide to what theories are important for understanding how to effectively incorporate purposeful VNR in instruction. It recommends that visual notetaking is a powerful teaching tool that teachers should embrace.

\section{Limitations and Future Research}

Our study was constrained by several limitations, which point to several directions for future research.In this qualitative study, the researchers were looking for a deeper and richer understanding of VNR, and therefore the perspectives of only five participants can be considered a limitation. The other limitation is that the study was not conducted in one research setting. The participants in this study included experts in business, and only one respondent was from the field of education. In other words, the focus was not on the importance of visual note recording in education, especially how VNR can effect learning. Future research could interview teachers or lecturers as well as students in schools or higher educational institutions who have been applying VNR in an academic setting. Teachers can be questioned about how they teach students to include VNR as a learning technique that could possibly be as important as reading and writing. Students can be asked about their attitudes toward learning, and using visual note recording for learning. Exploring the attitudes of students using VNR can add depth to the understanding of the usefulness of incorporating this tool into other learning strategies.

\section{References}

Adams, W. (2015). Conducting Semi-Structured Interviews, In Handbook of practical program evaluation, Kathryn E Newcomer; Harry P Hatry; Joseph S Wholey (eds), Hoboken, NJ : Jossey-Bass.

Ainsworth, S., Prain, V., \& Tytler, R. (2011). Drawing to learn in science. Representations, 3, 1-5. Andrade, J. (2010). What does visual note recording do? Applied Cognitive Psychology, 24, 100-106.

Beatty, N. A. (2013). Cognitive visual literacy: From theories and competencies to pedagogy. Art Documentation: Journal of the Art Libraries Society of North America, 32(1), 33-42.

Braun, V. \& Clarke, V. (2012). Thematic analysis. In Cooper, H. (Ed.), The Handbook of Research Methods in 
Psychology. Washington, DC: American Psychological Association.

Brodsky, A. (2008). Negative case analysis. In L. Given (Ed.), The SAGE encyclopedia of qualitative research methods. (p. 553). Thousand Oaks, CA: SAGE. doi: http://dx.doi.org/10.4135/9781412963909.n283

Brown, S. (2014). The doodle revolution. New York, published by the Penguin Group.

Brumberger, E. (2011). Visual literacy and the digital native: An examination of the millennial

learner. Journal of Visual Literacy, 30(1), 19-46.

Carcary, M. (2009). The Research Audit Trial-Enhancing Trustworthiness in Qualitative Inquiry. The Electronic Journal of Business Research Methods 7(1), 11-24.

Childers, P. B., Hobson, E. H., \& Mullin, J. A. (2013). ARTiculating: Teaching writing in a visual world. Fort Collins, CO: The WAC Clearinghouse. (Originally published 1998, Portsmouth, NH: Boynton/Cook.) Retrieved from https://wac.colostate.edu/ books/landmarks/articulating

Creswell, J. W. (2012). Qualitative inquiry and research design: Choosing among five approaches. Thousand Oaks, CA: Sage.

Dodgson, J.E. (2019). Reflexivity in Qualitative Research Journal of Human Lactation 35(2), 220-222 https://doi.org/10.1177/0890334419830990

Elkins, J. (2008). Introduction: The Concept of Visual Literacy, and Its Limitations, In: Visual literacy, (ed) James Elkins New York: Routledge.

Ertmer, P. A., \& Newby, T. J. (2013). Behaviorism, cognitivism, constructivism: Comparing critical features from an instructional design perspective. Performance Improvement Quarterly, 26(2), 43-71

Felton, P. (2008). Visual literacy. Change: The magazine of higher learning, 40(6), 60-64.

Fernández-Fontecha, A., O’Halloran, K. L., Tan, S. \& Wignell, P. (2016). A Multimodal Approach to Visual Thinking: The Scientific Sketchnote. Visual Communication. 18(1), 5-29 https://doi.org/10.1177/1470357218759808

Fusch, P.I., \& Ness, L.R. (2015). Are We There Yet? Data Saturation in Qualitative Research The Qualitative Report 20(9), 1408-1416.

Goldschmidt, G. (2001). Visual analogy: A strategy for design reasoning and learning. Design knowing and learning: Cognition in design education, 199-220.

Haydon, T., Mancil, G.R., Kroeger, S.D., McLeskey, J., \& Lin, W.J. (2011). A review of the effectiveness of guided notes for students who struggle learning academic content. Preventing School Failure: Alternative Education for Children and Youth, 55(4), 226-231. http://doi.org/10.1080/1045988X.2010.548415

Korstjens, I., \& Moser, A. (2018). Series: Practical guidance to qualitative research. Part 4: Trustworthiness and publishing, European Journal of General Practice, 24(1), 120-124, https://doi.org/10.1080/13814788.2017.1375092

Lincoln, YS. \& Guba, EG. (1985). Naturalistic Inquiry. Newbury Park, CA: Sage Publications.

Lohr, L. (2008). Creating Graphics for Learning and Performance: Lessons in Visual Literacy, (2nd Ed.). Cleveland, OH: Prentice-Hall.

Matusiak, K.K. \& Heinbach, C. \& Harper, A. \& Bovee, M.. (2019). Visual literacy in practice: Use of images in students' academic work. College and Research Libraries. 80(1) 123-139.

Mayer, R. E. (2009). Multimedia Learning ( $2^{\text {nd }}$ ed.). New York: Cambridge University Press.

Merriam, S. B. (2009). Qualitative research: A guide to design and implementation. San Francisco, CA: JosseyBass.

Mccormack A.J. (2017). Developing Visual/Spatial Thinking in Science Education. In: Taber K.S., Akpan B. (eds) Science Education. New Directions in Mathematics and Science Education. Sense Publishers, Rotterdam.

McGregor, T. (2018). Ink and Ideas: Sketchnotes for Engagement, Comprehension, and Thinking. Heinemann Educational Books, Portsmouth NH.

Mills, E. (2019). The Art of Visual Notetaking: An interactive guide to visual communication and sketchnoting Mission Viejo, CA: Walter Foster Publishing.

Moeller, M., Cutler, K., Fielder, D., \& Weier, L. (2013). Visual Thinking = Creative and Critical Thinking. Phi Delta Kappan. 95, 56-60. 10.1177/003172171309500312

Moorman, M. M. (2013). "The Meaning of Visual Thinking Strategies for Nursing Students". UNLV Theses/Dissertations/Professional Papers/Capstones. Paper 1946.

Paepcke-Hjeltness, V., Mina, M., \& Cyamani, A. (2017). Sketchnoting: A New Approach To Developing Visual Communication Ability, Improving Critical Thinking And Creative Confidence For Engineering And Design Students. Frontiers in Education Conference (FIE) (pp. 1-5). IEEE.

Paepcke-Hjeltness, V., \& Lu, T. (2018) Design for visual empowerment: Sketchnoting, breaking the rules International Design Conference for Design, New Orleans, LA, Sept 2018. Industrial Designers Society of America. http://www.idsa.org/educationpaper/design-visual-empowerment

Paepcke-Hjeltness, V. \& Cyamani, A. (2017). Enhancing Creative Confidence through Sketchnoting, A Foundational Research Exploration. University of Cincinnati. 
Paivio, A. (1990). Mental Representations: A Dual Coding Approach. Oxford University Press.

Pillars, W. (2016). Visual note-taking for educators: A teacher's guide to studentc reativity. Norton, W. W. \& Company, Inc. London

Pfister, R., \& Eppler, M. (2012). The benefits of sketching for knowledge management, Journal of Knowledge Management, 16, 372-382.

Pritchard, A. (2009). Ways of Learning: Learning theories and learning styles in the classroom (2 ${ }^{\text {nd }}$ ed) New York, NY: Routledge.

Pritchard, A., \& Woollard, J. (2010). Psychology of the classroom: Constructivism and social learning, New York, NY: Routledge.

Rohde, M. (2013). The sketchnote handbook: The illustrated guide to infographics. San Francisco, CA: Peachpit Press.

Sadoski, M., \& Paivio, A. (2012). Imagery and Text: A Dual Coding Theory of Reading and Writing (2 ${ }^{\text {nd }}$ ed), New York, NY: Routledge.

Saunders, B., Sim, J., Kingstone, T., Baker, S., Waterfield, J., Bartlam, B., ... Jinks, C. (2018). Saturation in qualitative research: exploring its conceptualization and operationalization. Quality \& quantity, 52(4), 18931907. http://doi.org/10.1007/s11135-017-0574-8

Schott, G. D. (2011). Visual note recording and the default network of the brain. The Lancet, 378(9797), 11331134.

Semetko, H. A., \& Scammell, M. (2012). The SAGE handbook of political communication London, UK: Sage. http://dx.doi.org/10.4135/9781446201015

Stacy, E.M., \& Cain, J. (2015). Note-taking and handouts in the digital age. American Journal of Pharmaceutical Education.79(7), $107 \mathrm{http}: / / \mathrm{dx}$. doi.org/10.5688/ajpe797107

Thomas, D. R. (2006). A general inductive approach for analyzing qualitative evaluation data. American Journal of Evaluation, 27(2), 237-246.

Tillmann, A. (2012). "What We See and Why It Matters: How Competency in Visual Literacy can Enhance Student Learning" (2012). Honors Projects. Paper 9. Retrieved from: http://digitalcommons.iwu.edu/education_honproj/9

Trafton, A. (2014). In the blink of an eye. MIT News, Jan 16, 2014 Retrieved from: http://news.mit.edu/2014/inthe-blink-ofan-eye-01.16

Udomon, I., Xiong, C., Berns, R., Best, K., \& Vike, N. (2013). Visual, Audio and Kinesthetic Effects on Memory Retention and Recall. Journal of Advanced Student Science. 2013(1), 1-29.

Vygotsky, L. (1978). Mind in Society. Cambridge, MA: Harvard University Press.

Walker, M. (2012). "Visual Thinking: Sketching my Future as a Visual Practitioner". Creative Studies Graduate Student Master's Projects. Paper 156. E.H. Butler Library at Buffalo State College Digital Commons at Buffalo State.

Wammes, J., Meade, M., \& Fernandes, M. (2016). The drawing effect: Evidence for reliable and robust memory benefits in free recall. In The Quarterly Journal of Experimental Psychology, 69(9), 1752-1776.

Wilson, M. L. (2011). Students' Learning Style Preferences and Teachers' Instructional Strategies: Correlations between Matched Styles and Academic Achievement (Doctoral dissertation, Liberty University).

Zucker, L. (2019). Embracing Visual Notetaking English Journal 108(6), 97-99. 